INTERMATIONAL JOURNAL
OFE
PHARMACEUTICAL SCIENCES
RESEARCH

Received on 26 July 2019; received in revised form, 29 January 2020; accepted, 29 February 2020; published 01 June 2020

\title{
IN-VIVO EFFECT OF WITHACOAGULIN AND COAGULIN C ISOLATED FROM WITHANIA COAGULANS DUNAL FRUITS ON BLOOD PRESSURE OF ALBINO RATS
}

Quaisul Hoda ${ }^{* 1 a, b}$ and Ketan P. Modi ${ }^{2}$

Department of Pharmacy ${ }^{1 a}$, R K University, Rajkot - 360020, Gujarat, India.

Ram-Eesh Institute of Vocational and Technical Education ${ }^{1 b}$, Greater Noida - 201310, Uttar Pradesh, India.

Gandhi Nagar College of Pharmacy ${ }^{2}$, Gandhi Nagar - 382010, Gujarat, India.

Keywords:

Withacoagulin, Coagulin C, Withania coagulans, Dunal fruits, Antihypertension, Verapamil

\section{Correspondence to Author:}

Mr. Quaisul Hoda

Ph.D Scholar,

Department of Pharmacy,

R K University, Rajkot - 360020,

Gujarat, India.

Assistant Professor,

Department of Pharmacy,

Ram-Eesh Institute of Vocational and Technical Education, Greater

Noida - 201310, Uttar Pradesh, India.

E-mail: quaisulhoda@yahoo.co.in
ABSTRACT: The present study was designed to evaluate the in vivo effect of withacoagulin and coagulin $\mathrm{C}$ isolated from Withania coagulans Dunal fruits on blood pressure of albino rats. DOCA $(10 \mathrm{mg} / \mathrm{kg}$; i.p. $)$ along with diet high in sodium chloride salt was used to induce hypertension in rats. Comparative effects of withacoagulin and coagulin $\mathrm{C}$ isolated from Withania coagulans Dunal fruits were observed. Female Albino rats (100-120 g) were divided into seven experimental groups ( $\mathrm{n}=$ 6). Normal control, Verapamil standard control (50 mg/kg, p.o.), withacoagulin treatment groups $(25,50 \mathrm{mg} / \mathrm{kg} ;$ p.o.), coagulin C treatment groups $(25,50 \mathrm{mg} / \mathrm{kg}$; p.o.) and Toxic control (DOCA with $2 \%$ normal saline ad libitum). Rats having more than $150 \mathrm{~mm} \mathrm{Hg}$ systolic blood pressure were chosen for the treatment. Noninvasive tail blood pressure amplifier (NIBP200A) was used to measure the blood pressure of conscious rats at a fixed interval of time every day for four weeks. A significant decrease $(\mathrm{P}<0.05)$ in the blood pressure of withacoagulin treated and the standard group was observed. Withacoagulin at dose 25 $\mathrm{mg} / \mathrm{kg}$ produced significant $(\mathrm{P}<0.05)$ antihypertensive effect. Withacoagulin at $50 \mathrm{mg} / \mathrm{kg}$ dose produced a highly significant antihypertensive effect $(\mathrm{P}<0.001)$ as compared to verapamil. Coagulin $\mathrm{C}$ has been found to have no significant antihypertensive effect on albino rats.
INTRODUCTION: Hypertension (HTN) or high blood pressure (BP) is the most common cardiovascular disease and is a major public health issue in developed as well as developing countries. It is a chronic medical condition in which the blood pressure in the arteries is elevated.

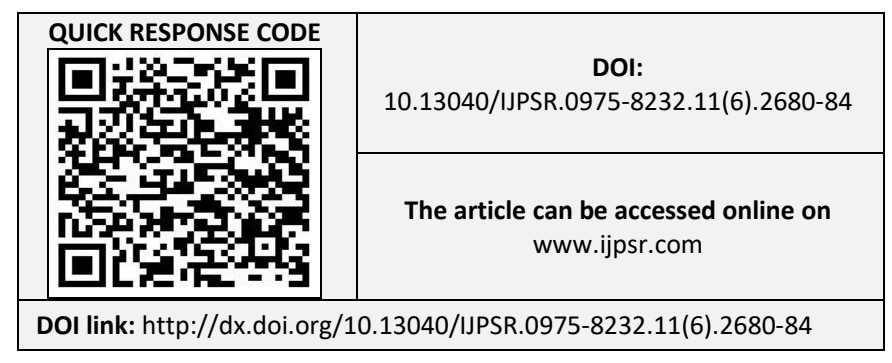

Hypertension is classified as either primary (essential) or secondary. Essential hypertension in humans is a complex, multifactorial, quantitative trait under polygenic control. About 90 to $95 \%$ of cases are considered primary HTN, which refers to high BP of unknown etiology ${ }^{1}$.

The remaining 5 to $10 \%$ of cases, called secondary HTN, are caused by adverse effects on kidneys, arteries, heart, or endocrine system ${ }^{2}$. Long term HTN is one of the risk factors for strokes, heart attacks, heart failure, and arterial aneurysm, and is a leading cause of chronic kidney failure ${ }^{3}$. Because of its high incidence and morbidity, various classes 
of drugs and regimens have been advocated for the control of hypertension. Despite the large armamentaria of drugs being available for the treatment of hypertension, the last two decades have witnessed the introduction of a number of new antihypertensive drugs. Evaluation of isolated compounds like withacoagulin and coagulin $\mathrm{C}$ as promising antihypertensive compounds of plant origin may lead to its addition to the list once it gets approval for a clinical trial.

Withania coagulans Dunal belongs to family Solanaceae and is a well-known medicinal plant in the indigenous system of medicine ${ }^{4}$. It is mainly distributed in the east of the Mediterranean region extending to South Asia including many parts of northern and western India ${ }^{5}$. The drug has been reported to possess anti-inflammatory ${ }^{6}$, antiurease effect by virtue of its property to inhibit COX-2 enzymes ${ }^{7}$, cardiotonic activities ${ }^{8}$, hepatoprotective 9 , antifungal ${ }^{10}$, hypoglycaemic ${ }^{11}$, hypolipidemic ${ }^{12}$ and anticancer activity ${ }^{13}$. Fruits of the plant have a milk-coagulating characteristic ${ }^{14}$. The fruits have been used for milk coagulation which is attributed to the enzymatic charisma of the plant ${ }^{15}$.

The aqueous extract of $W$. coagulans fruits in experimental rats have a diuretic potential ${ }^{16}$. The diuretic effects may be associated with the presence of the active principles of polar nature where withanolides are the main chemical protagonist of this activity. A withanolide (steroidal lactone) having a unique chemical structure similar to the aglycone part of cardiac glycoside has been shown to exert a cardiovascular effect. This withanolide produced a slight fall in blood pressure when observed in dogs. This effect could be blocked by atropine (cholinergic connection) and not by propranolol. In rabbits Langendorff preparation and ECG studies, produced myocardial depressant effects but in perfused frog heart it caused mild positive inotropic and chronotropic effects ${ }^{8}$.

MATERIALS AND METHODS: The study was approved by the Institutional Animal Ethics Committee (IAEC/RIT/02/16). Healthy, adult female albino rats weighing approximately 110-120 $\mathrm{g}$ were used for the study. They were kept in standard laboratory conditions under $12 \mathrm{~h}$ light and $12 \mathrm{~h}$ dark cycle. Hypertension in rats was induced by administering DOCA (10 mg/kg; i.p.).
The animals were kept on a diet high in sodium chloride (Golden Feeds, Mehrauli, New Delhi) and drinking water replaced by $2 \%$ sodium chloride solution ad libitum. All AR grade chemicals including DOCA used in the study were obtained from CDH Chemicals. Withacoagulin $(20 \beta, 27-$ Dihydroxy-1-oxo-(22R)-witha-2,5,24-tetraenolide) was isolated from Withania coagulans fruits by successive extraction and flux chromatography. The fruits were purchased from the local spice and herbs market in Delhi. The fruits were identified and authenticated by National Herbarium of cultivated plants (NHCP), Division of Plant Exploration and Germplasm Collection, National Bureau of Plant Genetic Resources, New Delhi and plant authentication number (NHCP/NBPGR/201409 ) has been retained. The fruits were shade dried, weighed and crushed for extraction and isolation of withacoagulin and coagulin $\mathrm{C}$.

\section{Isolation Scheme of Withacoagulin from} Withania Coagulans berries: Shade dried crushed fruits were macerated in a mixture of chloroform and ethanol (1:1) for three days by occasional shaking followed by filtration and drying in a rotary evaporator. A semisolid mass so obtained after drying was fractionated by solvent-solvent extraction. Crude extract so obtained was suspended in hot water and extracted three times with n-hexane using a separating funnel. The aqueous layer was separated and extracted with ethyl acetate. The organic layer was separated and dried in a rotary evaporator at $35{ }^{\circ} \mathrm{C}$ and ethyl acetate fraction (WCE) was obtained. WCE was subjected to normal phase column chromatography (silica gel 60, 230-400 mesh) using the mobile phase n-Hex: EA/5:1-0:1. Multiple fractions (100 $\mathrm{ml}$ each) were obtained and combined followed by column chromatography (sephadex LH20) using ethanol as the mobile phase. Later few fractions were combined and submitted to normal phase column chromatography (silica gel $60,5-40 \mu \mathrm{m}$ ) using the mobile phase n-Hex: EA/5:1-0:1. Finally, few more fractions were collected and combined. They were subjected to RP-MPLC (Bondesil-C18, $40 \mu \mathrm{m})$ by using the gradient mobile phase EtOH: $\mathrm{H}_{2} \mathrm{O} / 30: 70$. The collected fractions were dried to get withacoagulin. The obtained isolate was confirmed spectroscopically as withacoagulin ${ }^{17}$. 
Isolation Scheme of Coagulin C from Withania Coagulans Berries: The shade dried fruits of Withania coagulans were crushed and macerated in ethanol followed by filtration and evaporation to obtain the ethanolic extract. The extract was dissolved in $\mathrm{MeOH}$ and defatted with petroleum ether followed by treatment with $10 \%$ acetic acid solution. The acidic aqueous extract $(\mathrm{pH} \mathrm{2-3)}$ was partitioned with chloroform and the acidic fraction was subjected to silica gel column chromatography using n-hexane/ $\mathrm{CHCl}_{3}$ as the mobile phase. The fractions so collected were combined and repeated with $\mathrm{CH}_{2} \mathrm{Cl}_{2} / \mathrm{MeOH}$ mixtures as mobile phase. The fresh fractions collected were then subjected to silica gel coated TLC. The separated compound was washed and dried to obtain coagulin $\mathrm{C}$ and confirmed using chemical tests characteristic for alkaloid and spectroscopic methods.

Treatment Protocol: The animals were divided into seven main groups having six animals in each group. Animals were given DOCA (10 mg/kg; i.p.) for induction of hypertension along with $2 \% \mathrm{NaCl}$ solution with drinking water. After one week the hypertensives rats were selected for the study. Verapamil (50 mg/kg) was given as standard control. Two doses of withacoagulin $(25 \mathrm{mg} / \mathrm{kg}$ and $50 \mathrm{mg} / \mathrm{kg})$ and coagulin $\mathrm{C}(25 \mathrm{mg} / \mathrm{kg}$ and 50 $\mathrm{mg} / \mathrm{kg}$ ) were used for the evaluation of antihypertensive effect in albino rats.

TABLE 1: BLOOD PRESSURE RECORDINGS OF ANIMALS DURING TREATMENT FOR FOUR WEEKS

\begin{tabular}{|c|c|c|c|c|c|c|c|c|}
\hline \multirow{2}{*}{$\begin{array}{c}\text { Animal group } \\
(n=6)\end{array}$} & \multicolumn{2}{|c|}{$1^{\text {st }}$ Week } & \multicolumn{2}{|c|}{$2^{\text {nd }}$ week } & \multicolumn{2}{|c|}{$3^{\text {rd }}$ week } & \multicolumn{2}{|c|}{$4^{\text {th }}$ Week } \\
\hline & SBP & DBP & SBP & DBP & SBP & DBP & SBP & DBP \\
\hline Normal Control & $118 \pm 2$ & $82 \pm 1$ & $119 \pm 2$ & $82 \pm 1$ & $118 \pm 1$ & $91 \pm 1$ & $117 \pm 2$ & $92 \pm 1$ \\
\hline Withacoagulin (25 mg) & $167 \pm 2$ & $134 \pm 1$ & $160 \pm 1$ & $129 \pm 2$ & $148 \pm 1$ & $125 \pm 1$ & $137 \pm 1$ & $122 \pm 1$ \\
\hline Withacoagulin (50 mg) & $149 \pm 1$ & $106 \pm 2$ & $137 \pm 1$ & $103 \pm 2$ & $128 \pm 1$ & $86 \pm 1$ & $124 \pm 1$ & $85 \pm 2$ \\
\hline Coagulin C (25 mg) & $209 \pm 1$ & $148 \pm 1$ & $196 \pm 1$ & $152 \pm 1$ & $188 \pm 1$ & $150 \pm 2$ & $187 \pm 1$ & $144 \pm 1$ \\
\hline Toxic control & $250 \pm 2$ & $158 \pm 2$ & $258 \pm 1$ & $152 \pm 1$ & $261 \pm 2$ & $159 \pm 2$ & $268 \pm 2$ & $166 \pm 2$ \\
\hline
\end{tabular}

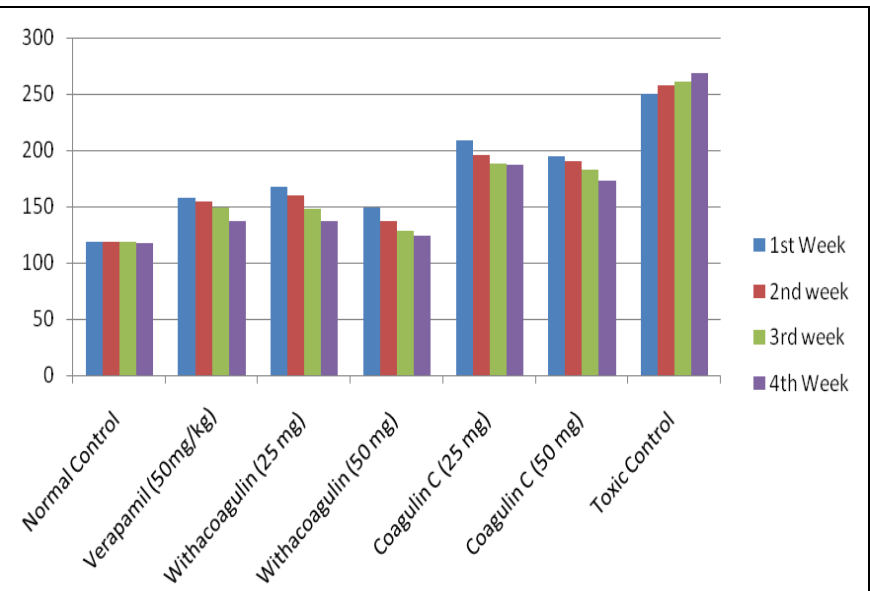

FIG. 1: COMPARATIVE EFFECT OF

WITHACOAGULIN AND COAGULIN C ON SYSTOLIC BLOOD PRESSURE OF EXPERIMENTALLY INDUCED HYPERTENSIVE ANIMALS

Blood Pressure Measurement: Monitoring and recording of blood pressure in experimental animals were done as per CPCSEA guidelines. NIBP200A (BIOPACK Systems Inc.) small animal tail noninvasive blood pressure amplifier was used to measure the blood pressure of experimentally induced hypertension in female albino rats on a daily basis for four weeks.

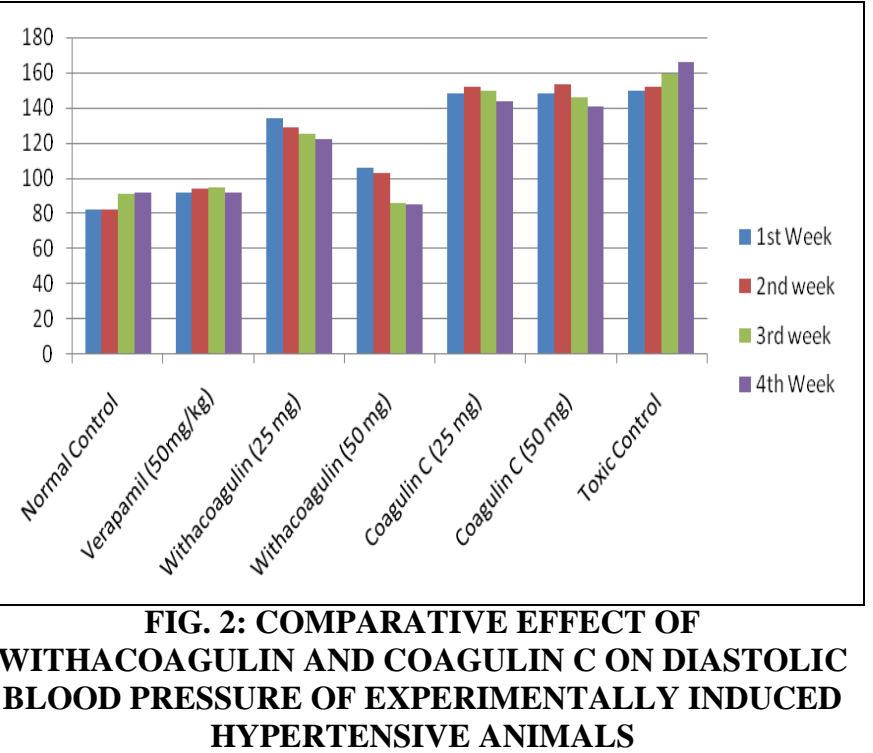

The instrument had an inbuilt pump Tail IRCUFFSENSOR which automatically inflated the cuff and occluded the rat tail blood vessel.

The cuff was deflated as soon as the pump reached the inflation point. Hereafter, a linear drop in blood pressure was recorded for each animal. 
Statistical Analysis: Standard mean and deviations were calculated for all variables of each group. One-way Analysis of Variance (ANOVA) was applied for statistical analysis with post-hoc analysis (Bonferroni Multiple Range Test) and Pvalue $<0.05$ has been considered as a statistical significance level.

RESULTS AND DISCUSSION: The present study is designed to evaluate the efficacy of withacoagulin isolated from Withania coagulans fruits in rat model of DOCA- induced hypertension. Withacoagulin group $(25 \mathrm{mg} / \mathrm{kg}$ and $50 \mathrm{mg} / \mathrm{kg}$ ) have shown a significant decrease in both systolic and diastolic blood pressure $(\mathrm{P}<0.05)$. Withacoagulin group (50 mg/kg) has shown a highly significant $(\mathrm{P}<0.001)$ decrease in both systolic and diastolic blood pressure of experimentally induced hypertensive animals.

Coagulin C group (25 and $50 \mathrm{mg} / \mathrm{kg}$ ) has no significant effect on the elevated blood pressure of hypertensive rats. Withania coagulans has been studied for its cardiotonic activity. The present study suggests that Withacoagulin isolated from W. Coagulans fruit has an antihypertensive effect in an experimental model of rat. Verapamil is a standard antihypertensive agent and decreases blood pressure by blocking $\mathrm{Ca}^{2+}$ channels in the smooth muscles of arteries.

On the basis of the fact that Withania coagulans is having $\mathrm{Ca}^{2+}$ channel blocking property ${ }^{18}$, the antihypertensive effect of withacoagulin might be through this mechanism. But the exact mechanism of action is still doubtful which needs further studies to confirm its antihypertensive effect. Withacoagulin at a dose of $50 \mathrm{mg} / \mathrm{kg}$ in rats has a better effect than standard verapamil which is a known antihypertensive drug in clinical use. Further studies can open a way for its clinical trial if studies confirm its safe use in experimental animals.

ACKNOWLEDGEMENT: We acknowledge sincere thanks to Ram-Eesh Institute of Technology for providing chemicals, laboratory, and animal house facilities. We are grateful to the Department of Pharmacy, Jamia Hamdard, for doing characterization of the isolated compounds. We are highly obliged to the Department of Pharmacology,
AIIMS, New Delhi for the support and guidance in completing this study.

CONFLICTS OF INTEREST: The author(s) have no conflicts of interest to disclose with anyone else.

\section{REFERENCES:}

1. Carretero OA and Oparil S: Essential hypertension. Part I: Definition and etiology. Circulation 2000; 101: 329-35.

2. Beevers G, Lip GY and O'Brien E: ABC of hypertension: The pathophysiology of hypertension. British Medical Journal 2001; 322: 912-6.

3. Pierdomenico SD, Di Nicola M, Esposito AL, Di Mascio $\mathrm{R}$, Ballone E and Lapenna D: Prognostic value of different indices of blood pressure variability in hypertensive patients. Am J Hypertensio 2009; 22: 842-7.

4. Kirthikar KR and Basu BD: Indian Medical Plants. Bishen Singh Mahendra Pal Singh, Delhi. Edition $2^{\text {nd }} 1933$.

5. Chadha YR: The Wealth of India. Publication and Information Directorate CSIR. New Delhi. 1976.

6. Budhiraja RD: Anti inflammatory activity of 3- $\beta$ hydroxy-2, 3-dihydro-withanolide F. Planta Med 1984; 50: 134-36.

7. Rehman PA, Mubshir H, Qamar A, Hussain R, Ihsan ul H, Seo SY and Kim SJ: In-vitro, in-silico elucidation of antiurease activity, kinetic mechanism and COX-2 inhibitory efficacy of coagulansin A of Withania coagulans. Chemistry \& Biodiversity 2018; 1: 15.

8. Budhiraja RD, Sudhir S and Garg KN: Cardiovascular effects of a withanolide from Withania coagulans Dunal. fruits. Indian Journal of Physiology and Pharmacology 1983; 27 (2): 129-34.

9. Budhiraja RD, Bala S, Craeg FN and Arora B: Protective effect of 3- $\beta$-hydroxy-2-3 dihydro withanolide $F$ against $\mathrm{CCl}_{4}$ induced hepatotoxicity. Planta Med 1986; 1: 28-29.

10. Choudhary MI, Dur-e-Shahwar, Zeba P, Jabbar A, Ali I and Rehman A: Antifungal steroidal Lactones from W. coagulans. Phytochemistry 1995; 40: 1243-46.

11. Hemalatha S, Wahi AK, Singh PN and Chansuria JP: Hypoglycemic activity of Withania coagulans Dunal. in streptozotocin induced diabetic rats. J Ethnopharmacol 2004; 93: 261.

12. Hemalatha S, Wahi AK, Singh PN and Chansuria JP: Hypolipidemic activity of aqueous extract of withania coagulans dunal in albino rats. Phytother Res 2006; 20: 614.

13. Ichikawa H, Takada Y, Shishodia S, Jayaprakasam B, Nair MG and Agarwal BB: Withanolides potentiate apoptosis, inhibit invasion, and abolish osteoclastogenesis through suppression of nuclear factor-kappaB (NF-kappaB) activation and NF-kappaB-regulated gene expression. Mol Cancer Ther 2006; 6: 1434-45.

14. Atal CK and Sethi PDA: Preliminary chemical examination of Withania coagulans. Indian J Pharm 1963; 25: 163-64.

15. Naz S, Masud T and Nawaz MA: Characterization of milk coagulating properties from the extract of Withania coagulans. Int J Dairy Technol 2009; 62: 315-20.

16. Dabheliya J, Khan SA, Joshipura M, Vasoya M, Patel S and Vijaya S: Diuretic potential of aqueous extract of fruits of W. coagulans Dunal in experimental rats. IJPPS 2010; $2: 4$ 
17. Shahwar Dur E: Isolation and structural studies on the withanolidal constituents of Withania coagulans. International center for chemical sciences. H.E.J. Research Institute of Chemistry, University of Karachi, Karachi 1999.
18. Niaz A, Bashir A, Shumaila B, Jehandar S, Sadiq A and Manzoor A: Calcium channel blocking activities of Withania coagulans. African Journal of Pharmacy and Pharmacology 2009; 3(9): 439-42.

How to cite this article:

Hoda Q and Modi KP: In-vivo effect of withacoagulin and coagulin c isolated from Withania coagulans dunal fruits on blood pressure of albino rats. Int J Pharm Sci \& Res 2020; 11(6): 2680-84. doi: 10.13040/IJPSR.0975-8232.11(6).2680-84.

All @ 2013 are reserved by the International Journal of Pharmaceutical Sciences and Research. This Journal licensed under a Creative Commons Attribution-NonCommercial-ShareAlike 3.0 Unported License.

This article can be downloaded to Android OS based mobile. Scan QR Code using Code/Bar Scanner from your mobile. (Scanners are available on Google Playstore) 